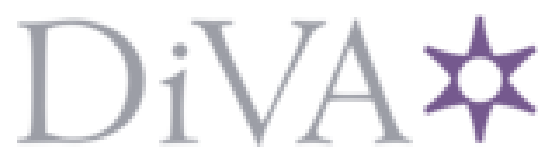

http://www.diva-portal.org

\title{
Postprint
}

This is the accepted version of a paper published in Tetrahedron Letters. This paper has been peerreviewed but does not include the final publisher proof-corrections or journal pagination.

Citation for the original published paper (version of record):

Lindström, U M., Olofsson, B., Somfai, P. (1999)

Microwave-assisted aminolysis of vinylepoxides.

Tetrahedron Letters, 40(52): 9273-9276

http://dx.doi.org/10.1016/S0040-4039(99)01811-0

Access to the published version may require subscription.

N.B. When citing this work, cite the original published paper.

Permanent link to this version:

http://urn.kb.se/resolve?urn=urn:nbn:se:su:diva-109690 


\title{
Microwave-assisted Aminolysis of Vinylepoxides
}

\author{
Ulf M. Lindström* and Berit Olofsson* \\ Department of Organic Chemistry, Arrhenius Laboratory, \\ Stockholm University, S-106 91 Stockholm, Sweden \\ Peter Somfai* \\ Organic Chemistry, Department of Chemistry, \\ Royal Institute of Technology, S-100 44 Stockholm, Sweden
}

\begin{abstract}
Di- and trisubstituted vinylepoxides in $\mathrm{NH}_{4} \mathrm{OH}$ were subjected to microwave irradiation affording the corresponding vicinal amino alcohols in high yields. The reaction is stereospecific and highly regioselective for addition at the allylic carbon.
\end{abstract}

Keywords: Amino alcohols; Aminolysis; Microwave heating; Ring-opening; Vinylepoxides.

Apart from being frequently occurring structural subunits in diverse natural products, vicinal amino alcohols own a fundamental position in asymmetric synthesis as 1,2-difunctional chiral auxiliaries and as building blocks for the preparation of biologically active compounds. ${ }^{1}$ Accordingly, a number of routes have been developed towards these structures. ${ }^{2}$ With the advancement of diastereo- and enantioselective syntheses of epoxides, cleavage of oxiranes by nitrogen nucleophiles has become one of the most investigated routes to vicinal amino alcohols. ${ }^{3}$ This strategy, however, is often limited by poor regioselectivity, except for terminal oxiranes (Scheme).

\section{Insert Scheme}

It has been shown that the steric and electronic influence of substituents on the oxirane ring control the regioselectivity of its ring opening reactions; conjugating substituents, e.g. phenyl and vinyl, usually promote ring opening at the adjacent carbon. ${ }^{4}$ We have previously reported that 1,2-disubstituted vinylepoxides can be ring-opened stereospecifically and highly regioselectively by ammonia and amines to afford the corresponding vicinal amino alcohols in good yields. ${ }^{5}$ This aminolysis reaction was successfully used in the enantioselective synthesis of $\mathrm{N}-\mathrm{H}$ vinylaziridines, compounds which have been used for the stereoselective construction of larger nitrogen heterocycles, ${ }^{6}$ and in the asymmetric synthesis of (+)-1-deoxynojirimycin. ${ }^{7}$ However, the scope of the reaction is limited as it requires prolonged heating in neat ammonia, and when sterically hindered substrates are used the reaction is almost completely retarded. Due to these difficulties, further investigation was necessary.

Stogryn and Brois have shown that monosubstituted vinylepoxides can be opened using $\mathrm{NH}_{4} \mathrm{OH},{ }^{8}$ but with more highly substituted substrates the reaction becomes too slow for synthetic purposes. With this procedure, vinylepoxide $\mathbf{1 a}$ gave amino alcohol $\mathbf{2 a}$ in only $13 \%$ yield after 10 days (Table 1, entry 1), whereas heating the same substrate in neat ammonia and tosic acid (0.05 eq) afforded $\mathbf{2 a}$ in $77 \%$ yield after 3 days (entry 2$)^{5}$

In recent years, the application of microwave-assisted reactions in organic synthesis has received considerable attention. Compared to conventional heating, microwave irradiation often gives greatly enhanced 
reaction rates and less byproducts. ${ }^{9-11}$ Gratifyingly, using a microwave assisted protocol we obtained 2a in 93\% yield in only 8 minutes (entry 3 ).

\section{Insert Table 1}

When we subjected di- and trisubstituted vinylepoxides 1a-g to microwave irradiation at $30 \mathrm{~W}$ in $\mathrm{NH}_{4} \mathrm{OH}$, complete conversion into amino alcohols $\mathbf{2 a - g}$ was generally obtained within 8 min (Table 2). ${ }^{12}$ The yields for the unhindered disubstituted substrates are better or as good as our previously reported results (entry 1,2). More sterically hindered substrates also seem to be efficiently converted into amino alcohols, as derivative 1c gave a yield of $90 \%$ compared to only $23 \%$ after 4 days in neat ammonia at $130^{\circ} \mathrm{C}$ (entry 3 ). The procedure is effective even for trisubstituted substrates (entry 4,5); the 1,2,2-trisubstituted vinylepoxide 1d afforded $\mathbf{2 d}$ in $76 \%$ yield whereas the cyclic substrate $\mathbf{1 e}$, with a quaternary allylic carbon, gave $\mathbf{2 e}$ and its regioisomer (1:1) in a combined yield of $77 \%$. The latter results are remarkable, as trisubstituted substrates were inert or reacted sluggishly using the original protocol. Aminolysis of $\mathbf{1 f}$ gave a 2:1 mixture of amino alcohol $2 \mathbf{f}$ and its regioisomer, reflecting a competition between the allylic and benzylic position (entry 6). More surprisingly, 1g also gave a regioisomeric mixture, the explanation for which is less obvious. Interestingly, by lowering the irradiation effect from $30 \mathrm{~W}$ to $5 \mathrm{~W}$ it was possible to suppress ring-opening of $1 \mathrm{~g}$ in the homoallylic position; the regioisomeric ratio was then increased from 6:1 to 9:1, although the reaction time needed to reach full conversion was longer.

To summarize, we have presented an efficient, microwave-assisted protocol for the regioselective and stereospecific synthesis of vicinal amino alcohols. Compared to previous methods, this procedure uses milder reaction conditions, shorter reaction times, generally gives higher yields and is applicable to a larger set of substrates. We are currently investigating the ring-opening of vinylepoxides by other nucleophiles using these conditions.

\section{Insert Table 2}

\section{Typical procedure}

Vinylepoxide $1 \mathrm{a}(0.086 \mathrm{mmol})$ in $\mathrm{NH}_{4} \mathrm{OH}(2.5 \mathrm{ml})$ was subjected to focused microwave irradiation at $30 \mathrm{~W}$ for 8 minutes. The solvent was evaporated at reduced pressure and the crude product chromatographed (EtOAc:MeOH 6:1+1\% $\mathrm{NH}_{3}$ ) to give amino alcohol 2a in 93\% yield.

\section{Acknowledgements}

This work was supported financially by the Swedish Natural Science Research Council and the Swedish Research Council for Engineering Sciences. Microwave equipment was kindly provided by Personal Chemistry ${ }^{T M}$.

\section{References and Notes}

1. Castejon, P.; Moyano, A.; Pericas, M. A.; Riera, A. Tetrahedron 1996, 52, 7063-7086.

2. Ager, D. J.; Prakash, I.; Schaad, D. R. Chemical Reviews 1996, 96, 835-875. 
3. Mitsunobu, O. Synthesis of amines and ammonium salts; Trost, B. M.; Fleming I., Ed.; Pergamon: Oxford, 1991; Vol. 6, Chapter 1.3.

4. Jaime, C.; Ortuno, R., M.; Font, J. J. Org. Chem. 1988, 53, 139-141.

5. Lindström, U. M.; Franckowiak, R.; Pinault, N.; Somfai, P. Tetrahedron Lett. 1997, 38, 2027-2030.

6. Lindström, U. M.; Somfai, P. Synthesis 1998, 109-117.

7. Lindström, U. M.; Somfai, P. Tetrahedron Lett. 1998, 39, 7173-7176.

8. Stogryn, E. L.; Brois, S. J. J. Am. Chem. Soc. 1967, 89, 605-609.

9. Caddick, S. Tetrahedron 1995, 51, 10403-10432.

10. Loupy, A.; Petit, A.; Hamelin, J.; Texier-Boullet, F.; Jacquault, P.; Mathé, D. Synthesis 1998, 1213-1233.

11. Stambouli, A.; Chastrette, M.; Soufiaoui, M. Tetrahedron Lett. 1991, 32, 1723-1724.

12. The relative configuration of each amino alcohol was determined by conversion into the corresponding oxazolidinone or aziridine. The trans-vinylaziridines obtained from anti-amino alcohols showed J=2.3-2.6 $\mathrm{Hz}$ and the cis-oxazolidinones prepared from the same precursors had $\mathrm{J}=7.8-8.1 \mathrm{~Hz}$, which is in accordance with the assigned structures. See Barrett, A. G. M.; Seefeld, M. A.; White, A. J. P. J. Org. Chem. 1996, 61, 2677-2685 and Pretsch, E.; Clerc, T.; Seibl, J.; Simon, W. Tables of Spectral Data for Structure Determination of Organic Compounds; Springer: Berlin, 1989. The relative configuration of compound $\mathbf{2 d}$ was determined by NOE-experiments on the corresponding oxazolidinone. 
Table 1. Investigation of the aminolysis of 1a

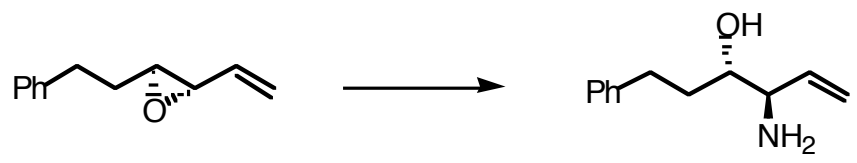

1a 2a

\begin{tabular}{clcc}
\hline Entry & \multicolumn{1}{c}{ Conditions } & Reaction time & Yield (\%) \\
\hline 1 & $\mathrm{NH}_{4} \mathrm{OH}, \mathrm{rt} \rightarrow \Delta$ & 10 days & 13 \\
2 & $\mathrm{NH}_{3}, \mathrm{TsOH} \cdot \mathrm{H}_{2} \mathrm{O}(0.05 \mathrm{eq}), 80{ }^{\circ} \mathrm{C}$ & 3 days & 77 \\
3 & $\mathrm{NH}_{4} \mathrm{OH}$, microwave irradiation, $30 \mathrm{~W}$ & $8 \mathrm{~min}$ & 93 \\
\hline
\end{tabular}


Table 2. Aminolysis of vinylepoxides ${ }^{\mathrm{a}}$

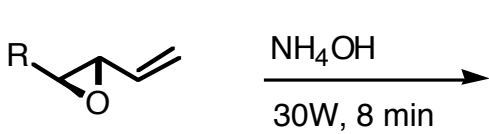

1a-g<smiles>[R]C(O)[C@@H](N)C=C</smiles>

2a-g

Entry

${ }^{a}$ All substrates were irradiated for $8 \mathrm{~min}$ at $30 \mathrm{~W}$ (except where noted). The reaction conditions have not been optimized for each substrate. ${ }^{\mathrm{b}}$ Isolated yields. Numbers in parenthesis refer to results obtained in neat $\mathrm{NH}_{3}$, TsOH$\cdot \mathrm{H}_{2} \mathrm{O}(0.05 \mathrm{eq})$ at $130^{\circ} \mathrm{C}\left(80^{\circ} \mathrm{C}\right.$ for entry 1$)$ for 3 days (4 days for entry $3) .{ }^{\mathrm{c}} 2 * 8 \mathrm{~min}, 30 \mathrm{~W} .{ }^{\mathrm{d}}$ Regioisomeric ratio $1: 1 .{ }^{\mathrm{e}} \mathrm{See}$ text. ${ }^{\mathrm{f}}$ Isolated as a $2: 1$ (4:1) regioisomeric mixture. ${ }^{\mathrm{g}}$ Regioisomeric ratio 6:1 (8 $\left.\mathrm{min}, 30 \mathrm{~W}\right), 9: 1$ (30 $\left.\mathrm{min}, 5 \mathrm{~W}\right)$. 


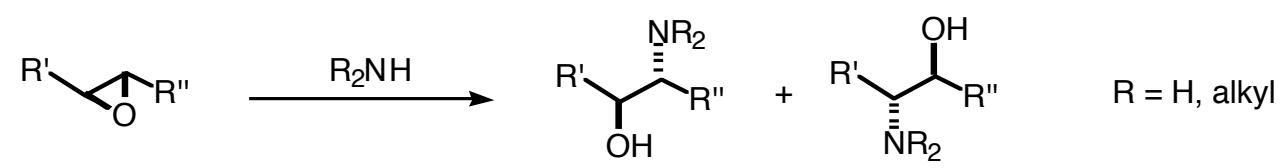

Scheme 